\title{
Inversion for Crustal Structure Using Reflections From the PASSCAL Ouachita Experiment
}

\author{
W. J. LutTer and R. L. Nowack \\ Department of Earth and Atmospheric Sciences, Purdue University, West Lafayette, Indiana
}

\begin{abstract}
An interface inversion has been tested and applied to wide-angle reflection data from the 1986 PASSCAL Ouachita experiment. An interface corrugation with a relief of $10 \mathrm{~km}$ and a width of $30 \mathrm{~km}$ was successfully imaged in a test of the interface inversion. Velocity-depth curves derived for shot points 14-19 using the tau-sum method are similar to an average one-dimensional velocity model from forward modeling using travel time correlations from southem profiles 14-19. The similarity of these velocity-depth curves positioned over the southem half of the PASSCAL experiment suggests that crustal structure in this region is approximately laterally homogeneous. Lower crustal velocities are not well resolved due to the recording on most profiles of only small segments of the travel time triplications. A two-dimensional velocity structure was derived by using the average one-dimensional velocities for the deeper crustal layers and formally inverting for depth to interfaces. The final inversion model is found to be consistent with previous refraction interpretations south of the Ouachita orogenic trend and concurrent interpretations of the PASSCAL data set. Inversion results for the central and southern portion of the PASSCAL profile indicate a depth of 10-12 km for a midcrustal layer which thins southward from approximately $10 \mathrm{~km}$ to about $4 \mathrm{~km}$. A lower crustal layer with an average thickness of $12 \mathrm{~km}$ and a Moho depth of approximately $29.5 \mathrm{~km}$ are also determined. Interface depths are in agreement with a normal moveout stack of the PASSCAL data set. In particular, the shallowing of the Moho to a depth of $30 \mathrm{~km}$ over the northern $50 \mathrm{~km}$ of the profile matches previous interpretations of the data set and has been interpreted here and in previous studies as the location of the Paleozoic continental margin. Geophysical studies of the modem Atlantic continental passive margin provide the simplest comparison to the crustal structure derived here. The lower crustal layer found south of the shallowing of the Moho to $30 \mathrm{~km}$ beneath the PASSCAL profile is analogous in thickness and position to rift stage lower crust. However, other tectonic interpretations are possible given the uncertainties in velocity and lithology relationships.
\end{abstract}

\section{INTRODUCTION}

The application of inversion methods to multiple shot refraction data sets improves data fitting and also gives a statistical measure of resolution and covariance of model parameters. Researchers who have applied inversion methods to refraction data sets include Ankeney et al. [1986], Benz and Smith [1984], Elbring [1984], Huang et al. [1986], Kanasewich and Chiu [1985], McMechan et al. [1982], and Spence et al. [1985]. Lutter et al. [this issue] inverted first arrival travel time data from the 1986 Program for Array Seismic Studies of the Continental Lithosphere (PASSCAL) Ouachita experiment with a velocity model parameterization consisting of a rectangular grid of splined velocity nodes. However, this parameterization only allowed for a smooth velocity gradient model without discontinuities.

The incorporation of an interface inversion into this inversion scheme allows the use of secondary reflected and refracted information to determine deeper crustal structure with model parameterizations which include velocity discontinuities at interfaces. The parameterization used in this paper allows for the inversion for interface position specified at splined node positions as well as velocities within layers specified by a rectangular splined grid. The advantages of such an inversion scheme include the facilitation of modeling a large volume of data such as the PASSCAL Ouachita experiment with a more realistic model parameterization. This study confines itself to the inversion for interface position utilizing wide-angle reflection arrivals.

Copyright 1990 by the American Geophysical Union.

Paper number 89JB03671.

0148-0227/90/89JB-03671\$05.00
An interface inversion is tested with synthetic data prior to application to the PASSCAL Ouachita data set. The laterally varying upper sedimentary velocities are assumed from the first arrival travel time inversion of Lutter et al. [this issue]. Velocities of deeper layers are determined from an average one-dimensional velocity model from wide-angle reflection travel time picks for profiles 14-19 located on the southern half of the PASSCAL experiment. The interface inversion is then applied to the wide-angle reflection data to obtain laterally varying midcrustal and Moho interface positions.

\section{PASSCAL OUACHITA EXPERIMENT}

The study area of the PASSCAL Ouachita experiment in southwestern Arkansas and northwestem Louisiana is along a major Paleozoic convergent continental margin. The experiment shown in Figure 1 overlays the southern third of a COCORP reflection profile across the Ouachita mountains and the Benton uplift. Twenty-one shots were fired into the array with an average shot spacing of $10 \mathrm{~km}$ for a total profile length of 200 $\mathrm{km}$. Four hundred seismographs were deployed in two separate profiles each $100 \mathrm{~km}$ in length. Keller et al. [1989] discuss more fully experimental design and objectives.

Data quality varies from profile to profile. First arrivals are clear out to $30-50 \mathrm{~km}$ for each shot point. Refracted energy for deeper interfaces are for the most part lost in noise except for profiles 1 and 16. Wide-angle and precritical reflections are observed on profiles $1,4,5,6$, and 10 along the northem portion of the experiment and on profiles 14-19 along the southem half of the experiment.

Reflection travel times from profiles 14-19 with shots positioned on the southern half of the PASSCAL experiment between 100 and $200 \mathrm{~km}$ are used to obtain an average onedimensional velocity model for the PASSCAL Ouachita 


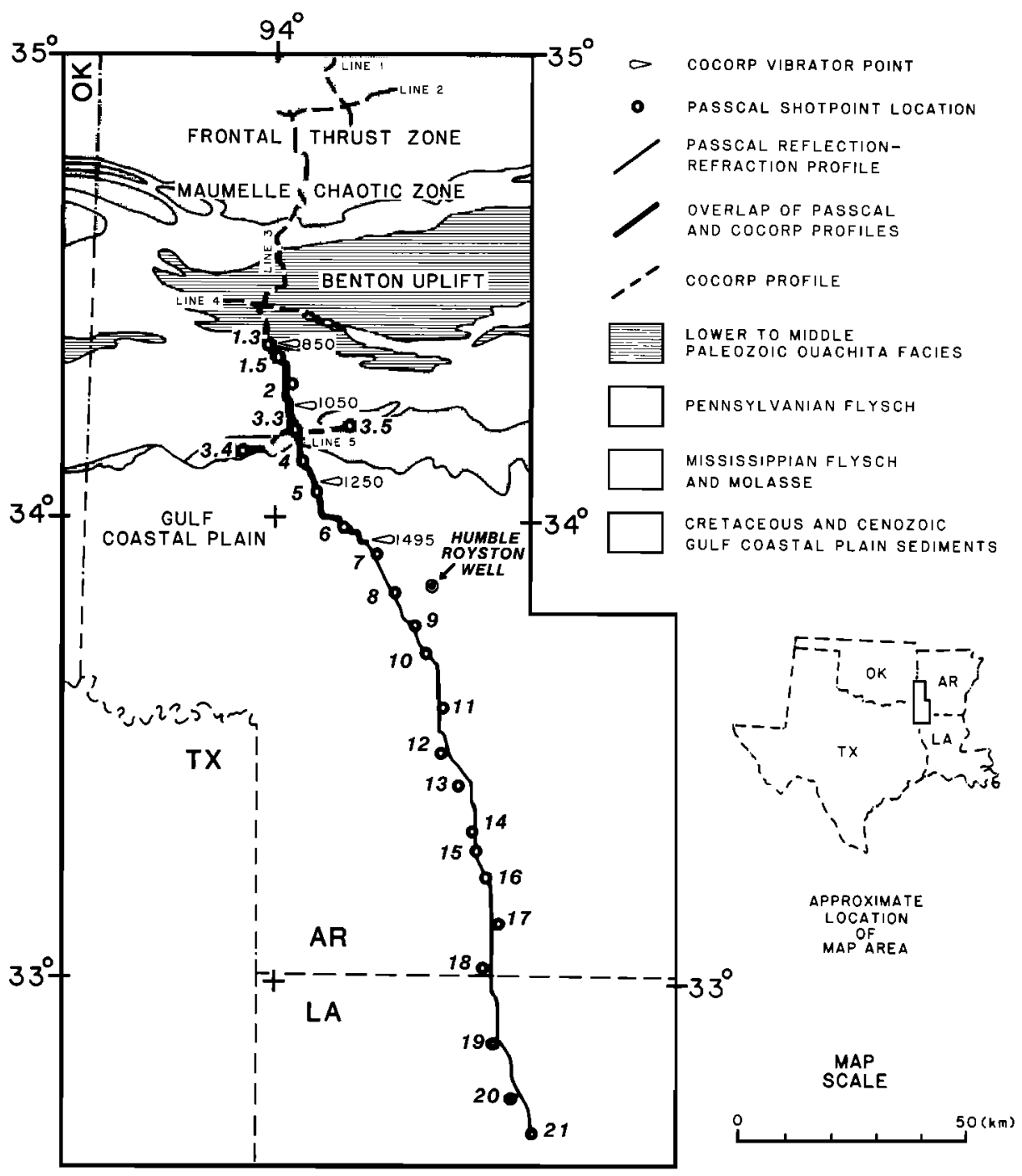

Fig. 1. Location map of the PASSCAL Ouachita experiment which overlays the southem third of the COCORP Ouachita Profile. The 21 PASSCAL shot points are indicated by numbered circles. For simplicity, we refer to data from each shot point (e.g., SP 4) as profile 4, or profile of shot point 4. Figure from Plappert [1988].

experiment. This average velocity model along with the laterally varying upper crustal model from Lutter et al. [this issue] is then used in the inversion for midcrustal and Moho interface locations.

\section{One-Dimensional Velocity Model}

Data from profile 14 with a shot point located $75 \mathrm{~km}$ from the southem end of the PASSCAL profile is displayed in Figure 2. Correlations associated with deep crustal structure are labeled and include reflections from upper and lower crustal interfaces and the Moho. Reflections may be coordinated using reciprocity between profiles 1 and 16 to the north and profiles 14-19 to the south. This is a useful constraint given the low signal to noise ratio and lack of complete triplication information. Travel time correlations match significant trends on automatic gain control (AGC) processed common shot gathers and are consistent with reciprocity constraints.

In Figure $2 a$, travel time curves from a flat layer onedimensional model which on average matches the travel time picks for southem profiles 14-19 are displayed. Superimposed on the curves are splined data picks from profile 14. That a one-dimensional model fits data from most southem profiles which contain correlatable reflected energy suggests strongly that crustal structure is approximately laterally homogeneous at least beneath the southern half of the PASSCAL experiment.

Velocities and depths from our average one-dimensional forward model are displayed in Figure $2 c$. Deeper crustal layers with velocities starting at 6.2 and $6.8 \mathrm{~km} / \mathrm{s}$ have depths to the upper interface of each layer of 12 and $16 \mathrm{~km}$, respectively. The Moho depth from profile 14 is approximately $27 \mathrm{~km}$.

Velocity-depth curves have also been derived from splined travel time picks for most of the southem profiles using the tau-sum method of Diebold and Stoffa [1981]. Tau-p values are calculated at equally spaced splined values using an analytic spline derivative. It is apparent from Figure 2 that a significant amount of the recorded reflected energy is precritical. Only distinct segments of the reflected correlations furthest from the shot point of each profile have been used to calculate tau-p values to avoid the inclusion of precritical reflected energy.

Velocity-depth curves determined by the tau-sum method for each profile are very similar to each other and to the average one-dimensional forward model. Averaging velocity-depth 

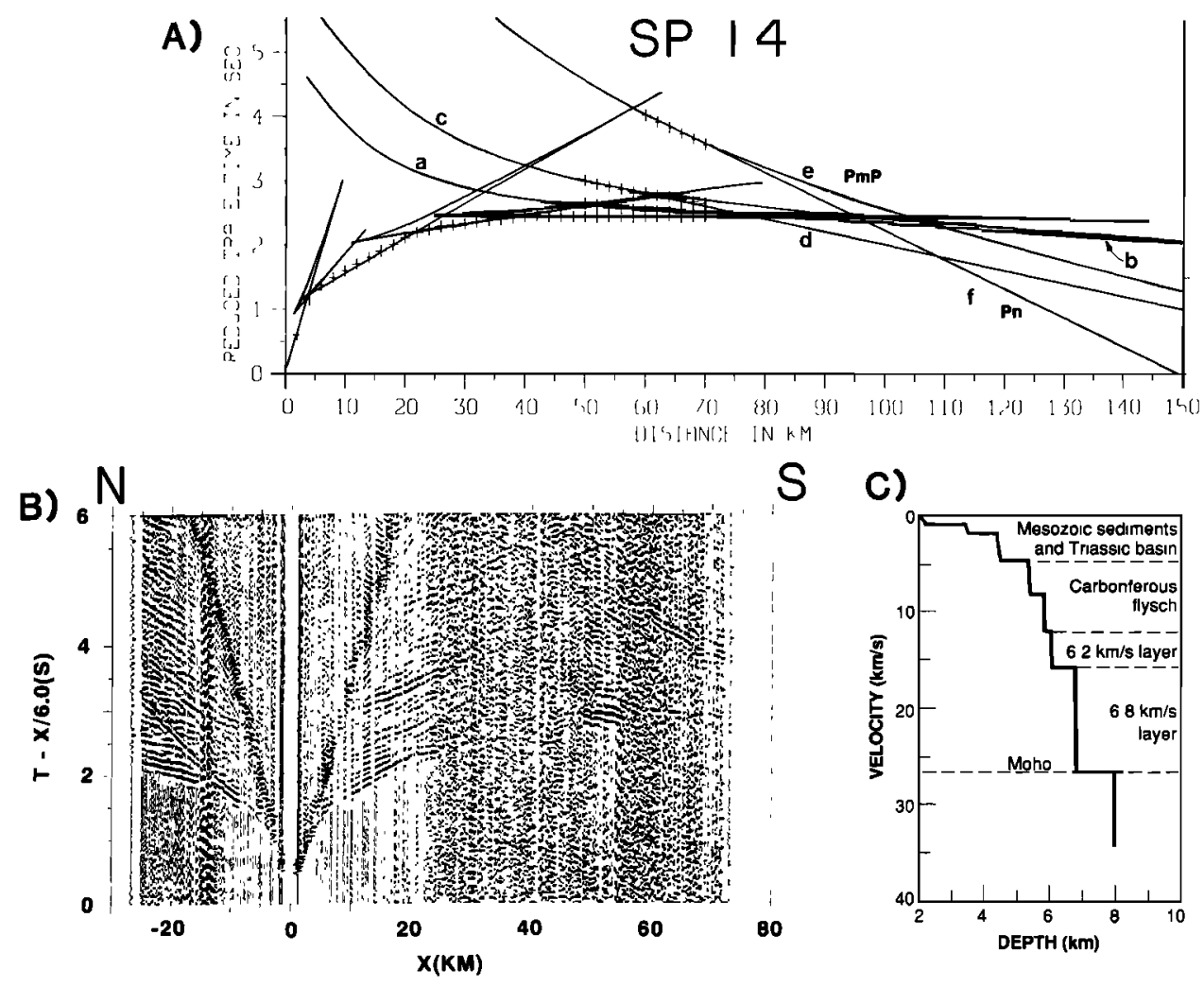

$S$ c)

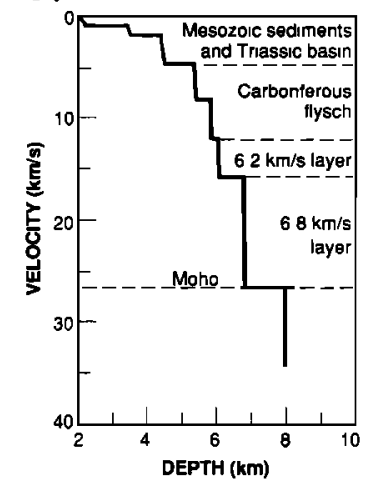

Fig. 2. (a) Splined travel time picks (crosses) from profile 14 are superimposed on travel time curves from a one-dimensional velocity model. Correlations are labeled: curve $a$, reflected energy from upper interface of $6.2 \mathrm{~km} / \mathrm{s}$ layer, curve $b$, refracted energy from $6.2 \mathrm{~km} / \mathrm{s}$ layer, curve $c$, reflected energy from upper interface of $6.8 \mathrm{~km} / \mathrm{s}$ layer; curve d, refracted energy from 6.8 $\mathrm{km} / \mathrm{s}$ layer, curve e, Moho reflected energy $\left(P_{m} P\right.$; curve $f$, refracted energy from uppermost mantle $\left(P_{n}\right)$. $(b)$ AGC processed split profile of shot point 14. (c) Velocity-depth curve of one-dimensional velocity model. Labeled velocities and depths can be associated with sedimentary units based on previous work [Jardine, 1988; Lutter et al., this issue] and deeper crustal layers.

curves calculated by the tau-sum method for the southern profiles $14-19$ yields velocities starting at $6.0,6.2$, and $6.8 \mathrm{~km} / \mathrm{s}$ at depths of $8.4,12.25$, and $16.5 \mathrm{~km}$ (dashed lines for profile 14 in Figure 3). Estimates of the Moho depth range from 28 to 31

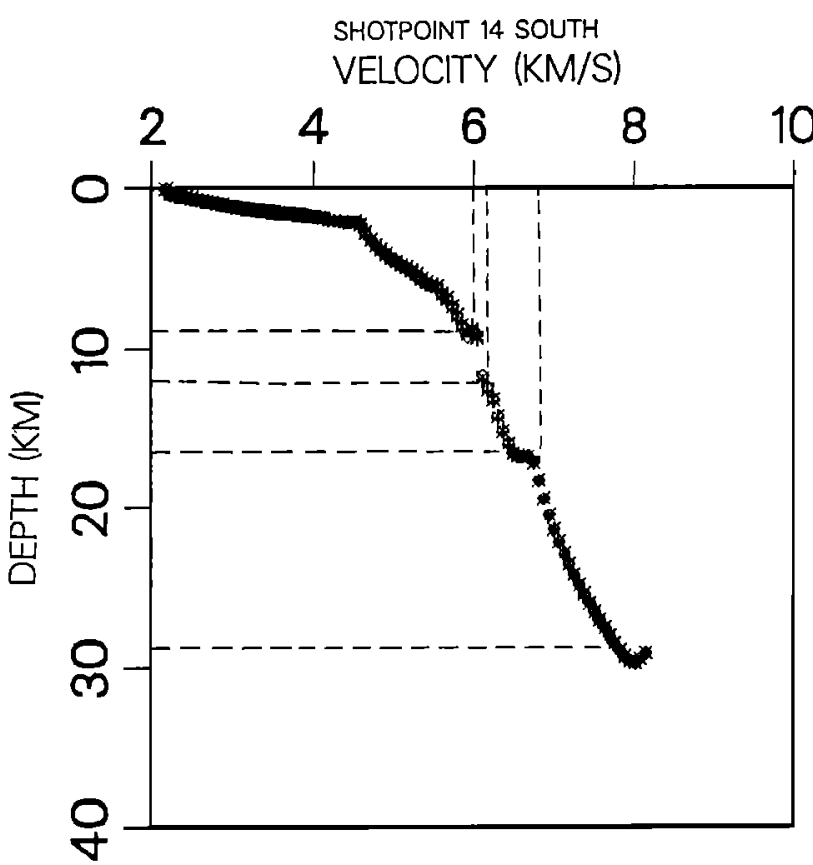

Fig. 3. Velocity-depth curve derived from the tau-sum method for profile 14 south. Dashed horizons are described in the text. km. The tau-sum estimates of depth are slightly greater than the depths of the average one-dimensional forward model shown in Figure 2. Also, since the portion of the triplication curved used to derive these velocity models only constrains velocities near the uppermost interface of each layer, deeper velocities and even average velocities are likely to be somewhat higher than values discussed above for the average onedimensional model.

Figure $4 b$ displays the AGC data from profile 16 which has a shot point located $134 \mathrm{~km}$ from the northern end of the experiment. Splined travel time picks at $2-\mathrm{km}$ intervals are displayed at the same scale in Figure $4 a$. To the north, several correlations are evident. Weak refracted energy from a 6.2 $\mathrm{km} / \mathrm{s}$ interface may be correlated from $-30 \mathrm{~km}$ to $-140 \mathrm{~km}$ from the shot point. Reflected and refracted energy from a $6.8 \mathrm{~km} / \mathrm{s}$ interface has a cusp position at approximately $70 \mathrm{~km}$. Reflected energy from the Moho is the most pronounced secondary arrival of the record section. To the south, reflections from the 6.2 and $6.8 \mathrm{~km} / \mathrm{s}$ interfaces and Moho are evident between 40 and 60 $\mathrm{km}$ from the shot point. The position of reflected phases and critical reflections appear to be at farther offset distances to the north (negative distances) than to the south. The indication of laterally varying structure on this profile and northern profiles necessitates the extension of the one-dimensional velocity model by inversion methods to image two-dimensional structure.

Lyslo and Nowack [this issue] derived a velocity-depth envelope from a slant stack of shot point 16 to the north. Their algorithm is not based on a travel time picking procedure; however, other restrictions such as the one-dimensionality of the 

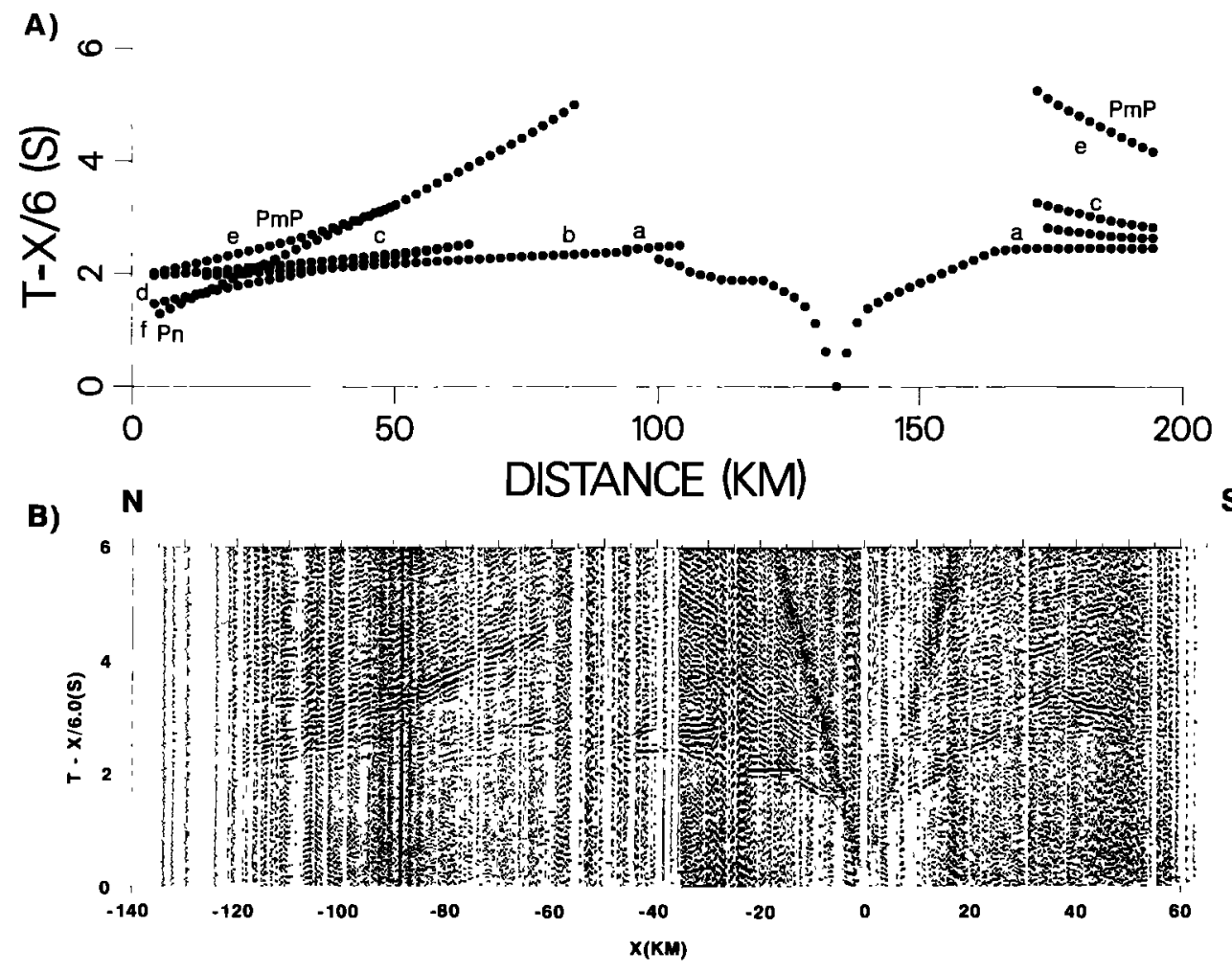

Fig. 4. (a) Splined travel time picks at same scale as the split profile of shot point 16. Correlations are labeled: curve a, reflected energy from upper interface of $6.2 \mathrm{~km} / \mathrm{s}$ layer, curve $b$, refracted energy from $6.2 \mathrm{~km} / \mathrm{s}$ layer; curve $c$, reflected energy from upper interface of $6.8 \mathrm{~km} / \mathrm{s}$ layer, curve d, refracted energy from $6.8 \mathrm{~km} / \mathrm{s}$ layer, curve e, Moho reflected energy $\left(P_{m} P\right)$; curve $f$, refracted energy from uppemost mantle $\left(P_{n}\right)$. (b) Split profile of shot point 16 plotted with AGC.

model are assumed. Our starting average one-dimensional model has a slower velocity in the lower crust than the detailed velocity function of Lyslo and Nowack [this issue]. This is to be expected from the lack of complete triplications recorded on the southern profiles. This may also be due to two dimensionality as well as truncation and phase shift effects on the slant stack procedure. However, our one-dimensional model is still within the velocity envelope derived from the slant stack procedure. Given the signal to noise ratio of the data and the assumptions and restrictions of the different methods applied to the PASSCAL Ouachita data, it is nonetheless encouraging that similar models have been inferred.

The average one-dimensional velocity model will be extrapolated to a two-dimensional velocity structure by assuming velocities for deeper crustal layers and inverting for depth to interfaces. A laterally varying upper crustal layer will also be used based on a velocity inversion of Lutter et al. [this issue]. Midcrustal and lower crustal average velocities are estimated to be constrained to $6.2 \mathrm{~km} / \mathrm{s} \pm 0.1$ and $6.9 \mathrm{~km} / \mathrm{s} \pm$ 0.3. Velocity gradients incorporating the one-dimensional velocities just beneath the uppermost interface for each layer have been used in the interface inversion (see Figure 13). The lower crustal velocity used is slightly slower on average than that of Lyslo and Nowack [this issue] or from our tau-sum velocity model. Higher velocities associated with deeper crustal layers would trade off with a slightly deeper Moho depth but would not significantly change the final two-dimensional image as derived by the interface inversion to follow.

\section{INTERFACE INVERSION}

The parameterization and the forward ray tracing used in the interface inversion are based on SEIS83 algorithm [Cerveny et al., 1977; Cerveny and Psencik, 1984]. A bicubic spline parameterization of velocity allows lateral and vertical gradients within layers. Layers are separated by splined interfaces and therefore velocity discontinuities can also be incorporated within the model.

The general nonlinear inversion procedure followed here is a layer-stripping approach for model parameters describing velocity within crustal layers or interface position at successively greater depths. A sequence of inversions is performed for each layer or interface starting with large node spacing to smaller node spacing of the model parameters. The linearized inversion procedure described here is similar for each type of model parameter (velocity or interface position nodes) and includes the calculation of partial derivatives after an initial ray trace, a linearized inversion step, and the calculation of statistics such as resolution and covariance. Refracted and reflected arrivals are sequentially used to invert for velocity nodes or interface position nodes at increasing depth within the model holding shallower model parameters fixed. This layerstripping strategy has been applied to both the synthetic and PASSCAL data inversions discussed in this paper by holding the velocities in the uppermost layer fixed and inverting for deeper crustal interface position.

For an interface inversion, rays are traced through a starting model in which splined interface depth is specified initially at a sparse number of node positions. Partial derivatives of travel time with respect to interface depth are determined by calculating and storing the spline coefficients for each perturbed interface node. The partial derivative of travel time with respect to an interface node have been derived and tested by Nowack and Lyslo [1989]. They can be written with respect to a perturbation at $x_{\text {node }}$ as [see Nowack and Lyslo, 1989, equation 6] 


$$
\frac{\partial T}{\partial z\left(x_{\text {node }}\right)}=\frac{\partial T}{\partial h\left(x_{a}\right)} \frac{\partial h\left(x_{a}\right)}{\partial z\left(x_{a}\right)} \frac{\partial z\left(x_{a}\right)}{\partial z\left(x_{\text {node }}\right)}
$$

where $x_{a}$ is the point of reflection/transmission and $\delta h$ is a local interface perturbation normal to the boundary at $x_{a}$. For the special case of a piecewise linear boundary and an incident reflected ray, this reduces to the result given by Bishop et al. [1985, equation B-10].

A linear system of equations relating travel time residuals $\delta T$ and model changes $\delta M$ can be inverted for corrections to the model which improve the data fit. These equations can be written

$$
\frac{\partial T_{i}}{\partial M_{j}} \delta M_{j}=\delta T_{i}
$$

for $i=1, m$ rays and $j=1, n$ model nodes. The introduction of damping stabilizes the inversion. The Paige and Saunders [1982] conjugate-gradient algorithm has been used to solve this system of equations and compares favorably with other methods of solving large tomographic systems [Nolet, 1985].

In the normal equation form, the damped least squares solution can be written

$$
m_{g}=\left(A^{T} A+\varepsilon^{2} I\right)^{-1} A^{T} d
$$

where $A$ is the partial derivative matrix, $m$ the model correction vector, $d$ the data residual vector, and $\varepsilon$ the damping parameter. The damping parameter can be related to the data standard error $\sigma_{D}$ and the a priori model parameter standard error $\sigma_{M}$ [see $A k i$ and Richards, 1980]:

$$
\varepsilon^{2}=\frac{\sigma_{D}^{2}}{\sigma_{M}^{2}}
$$

The damping parameter $\varepsilon$ can also be chosen to minimize the trade-off curve between spread of resolution and size of covariance [see Menke, 1984].

The iteration of the linearized inversion is continued until a stopping criterion based on an $F$ test is met [see Menke, 1984]. The density of node positions is then increased to allow greater variation in interface position and to lower the data residual vector. This sequence of inversions with an increasing number of nodes is also checked for significance of model improvement by use of a $F$ test. Values of the $F$ test less than a prescribed cutoff value stop the sequence of inversions at this depth level.

Model resolution and standard deviation of model parameters are calculated as described by Lutter et al. [this issue] and Nowack and Lutter [1988]. The resolution matrix acts as a filter on the true earth model parameters resulting in the estimated model $x_{g}=R x_{\text {irec }}$. Diagonal elements of the resolution matrix range between values of 0 to 1 . Nonzero diagonal elements indicate the degree of averaging or the linear dependence of the true model space as represented by the inverted model. Model parameters associated with diagonal elements of the resolution matrix $\geq 0.6$ are considered meaningful and well resolved. Ellsworth and Koyanagi [1977] used this arbitrary cutoff value due to artificially low a posteriori model covariance values for resolutions less than 0.5. However, the modified formula used here, results in increasing values of a posteriori covariance as resolution values decrease [Nowack and Lutter, 1988].

\section{SyNThetic DATA Inversion Test}

The inversion for interfaces is tested with synthetic data calculated from previously derived models associated with the PASSCAL Ouachita experiment. The shot-receiver geometry of the test inversion matches that of the PASSCAL experiment. For a given interface, a series of inversions incorporating an increasing number of equally spaced nodes along the interface is used to obtain a final image of an interface shape. The number of nodes used in the synthetic data test are 2, 5, 9, and 17 nodes. Approximately 100 rays are ray traced in each inversion iteration.

The model displayed in Figure 5 used to generate the synthetic data is based on two previous models with different parameterizations for the Ouachita data set [see Jardine, 1988; Lutter et al., this issue]. The interface at an average depth of $16 \mathrm{~km}$ contains an interface corrugation centered at $35 \mathrm{~km}$ with a relief of $4 \mathrm{~km}$ and a width of $30 \mathrm{~km}$. Rays with the same shot-receiver geometry as the Ouachita experiment which are reflected from this corrugated interface generate the synthetic data used in the inversion test.

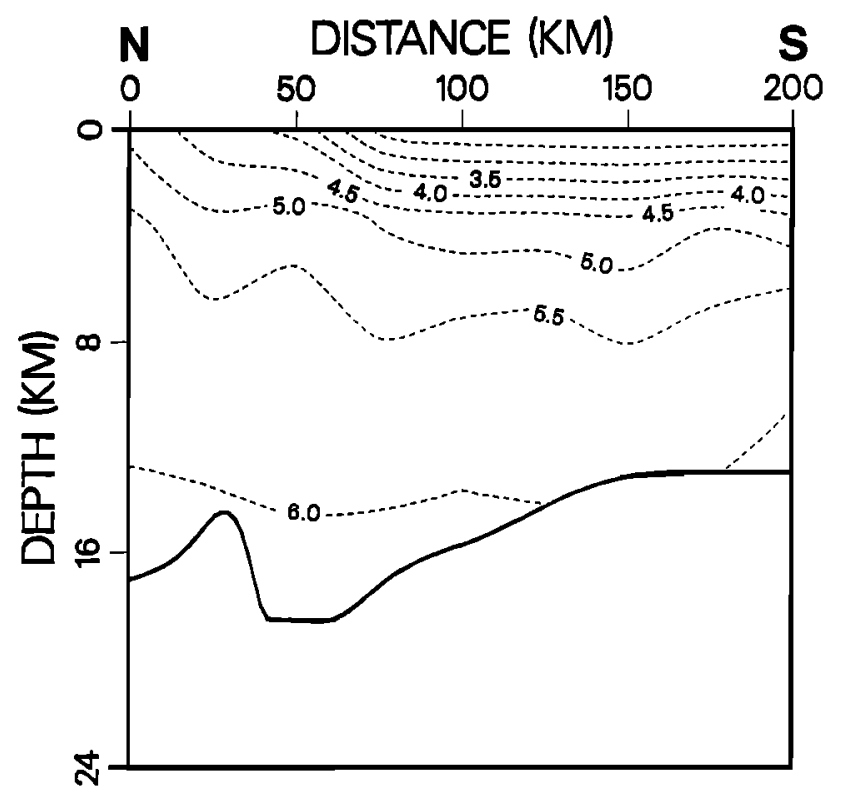

Fig. 5. Model used to generate synthetic data for interface inversion test. The isovelocity lines $(2.5-6.0 \mathrm{~km} / \mathrm{s})$ above a depth of $16 \mathrm{~km}$ are taken from Lutter et al. [this issue]. The interface at an average depth of $16 \mathrm{~km}$ is from Jardine [1988].

Figure 6 illustrates beginning (dashed) and final (solid) interface positions for a 2-node model (Figure 6a) and a 5-node model (Figure $6 c$ ). The beginning interface for the 2-node inversion with nodes positioned at 0 and $200 \mathrm{~km}$ starts with a flat layer at a depth of $15 \mathrm{~km}$. The final inverted interface for the 2-node case is a dipping interface. The 5-node interface inversion with nodes fixed horizontally at $0,50,100,150$, and $200 \mathrm{~km}$ begins with the dipping layer from the 2-node inversion and images a more complicated shape. However, the 4-km relief on the interface between 0 and $50 \mathrm{~km}$ is not imaged by either inversion.

Figures $6 b$ and $6 d$ illustrate the diagonal resolution values associated with each vertical node position. For the 2-node inversion resolution, values are above 0.7 . Resolution is above 0.75 at positions near 50 and $150 \mathrm{~km}$ for the 5 -node case 


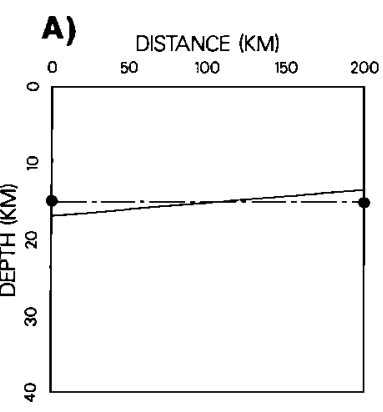

B)
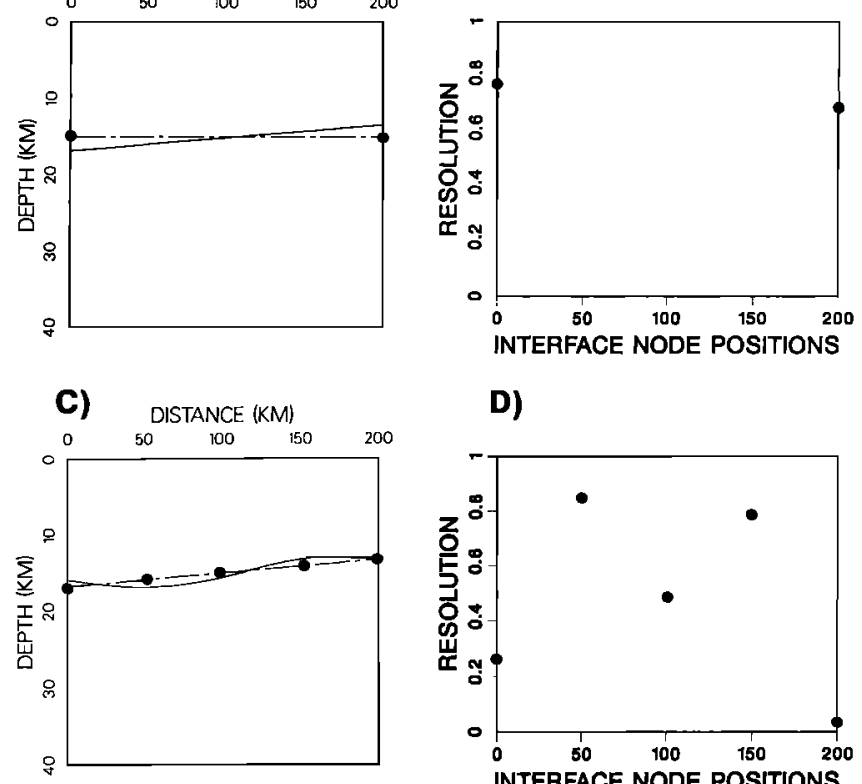

D)

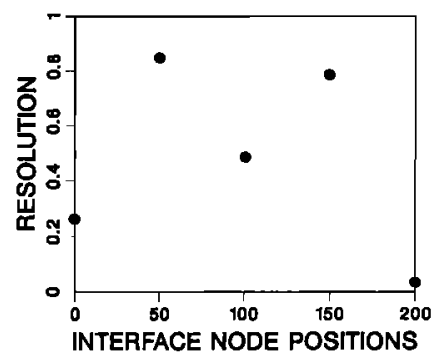

Fig. 6. (a) Dashed line shows beginning interface position for 2-node model. Solid dots indicate node positions on beginning interface. Solid line shows final interface position for 2-node model. (b) Resolution for each node position for 2-node model. (c) Dashed and solid lines for 5 node model are beginning and final interfaces. Solid dots indicate node positions on beginning interface. (d) Resolution for 5-node model.

mean-square (RMS) travel time error consistently drops as the number of model parameters increase. The starting model RMS error is $0.43 \mathrm{~s}$. The error drops to values of $0.25,0.15$ and 0.08 $s$ as interface node number increases from 2 to 5 to 9 nodes.

In Figures $7 a, 7 b$ and $7 c$ are displayed the travel time fit, a ray diagram, and resolution for a 17-node inversion. Reflected correlations from profiles 1, 4-6, 10, and 14-19 have been used in the inversion. Both a 9-node and a 17-node inversion (Figure $7 b$ ) image the interface relief and dip to the north. The RMS travel time error illustrated in Figure $7 a$ by the fit between theoretical (inversion model) and observed (synthetic data) travel times has dropped to $0.03 \mathrm{~s}$. Resolutions (Figure 7c) are above 0.5 between 25 and $62.5 \mathrm{~km}$ and between 125 and 162.5 $\mathrm{km}$ which are just within regions where rays reflect off the interface.

Figure 8 compares the original interface shape (dashed line) used to generate the synthetic data and the interface resulting from a 17-node inversion (solid line). The dip to the north between 50 and $150 \mathrm{~km}$ and relief on the interface between 0 and $50 \mathrm{~km}$ are imaged by the inversion. Even in regions where resolution drops below $0.4(0-12.5 \mathrm{~km}, 87.5-112.5 \mathrm{~km}$, and $175-200 \mathrm{~km}$ ) the general trend of the interface is maintained. By standards of data fit, degree of match between inverted and true models and coordination between resolution and ray coverage the interface inversion has successfully converged. The eight automatic ray tracings of 100 rays from 17 shots used to invert sequentially 2-, 5-, 9-, and 17-node models as well as calculate RMS error for this example has resulted in a considerable saving of man-effort and computer time over forward modeling.

\section{Application OF INTERAFace INVERSiON TO PASSCAL DATA}

The interface inversion described above is now used to invert data from the 1986 PASSCAL Ouachita experiment. Velocity gradients with average velocities of approximately 6.2 and 6.9 $\mathrm{km} / \mathrm{s}$ based on the average one-dimensional velocity model developed for profiles 14-19 have been used for the deeper layers. A layer-stripping procedure has been used to sequentially invert for the upper interface of the mid and lower crustal layers and the Moho.

Reflected travel time correlations from northem profiles 1,4 , 5,6 , and 10 and southern profiles 14-19 have been used in the inversion. Travel time correlations are sampled at $1-\mathrm{km}$ intervals. Inversions using either 9 or 12 nodes are discussed for each interface.

Figure $9 b$ displays half of the 300 rays used to invert for the second interface (upper interface of the $6.2 \mathrm{~km} / \mathrm{s}$ layer). Nodes are positioned every $12.5 \mathrm{~km}$ horizontally between distances of 0 and $100 \mathrm{~km}$ and every $25 \mathrm{~km}$ between 100 and $200 \mathrm{~km}$. Figure $9 a$ illustrates the travel time fit between observed data (solid circle) and inversion theoretical data (cross) for profiles 1, 4-6, 10, and 14-19. The RMS error for the entire data set used to invert for the $6.2 \mathrm{~km} / \mathrm{s}$ interface is $0.059 \mathrm{~s}$, but drops to $0.046 \mathrm{~s}$ for correlations from profiles 14-19. Figures $9 b$ and $9 c$ illustrate that interface segments from which rays reflect are associated with resolutions greater than 0.5 . Resolution is acceptable to excellent in areas of good ray reflection coverage. Off-diagonal elements of the resolution matrix are small. Between 125 and $175 \mathrm{~km}$ where resolution values are greater than 0.6 , the average depth of $11.6 \mathrm{~km}$ is close to the depth of $12 \mathrm{~km}$ derived from the one-dimensional velocity model.

The 330 rays used for the inversion of the third interface (upper interface of the $6.9 \mathrm{~km} / \mathrm{s}$ layer) resulted in resolutions above 0.55 for all interface regions except at 0 and $200 \mathrm{~km}$ (see Figures 10a-10c). The RMS error of $0.069 \mathrm{~s}$ for southem profiles 14-19 indicates an excellent fit given the complexity of the first layer velocity model and second interface. An average depth of $15.7 \mathrm{~km}$ between 125 and $175 \mathrm{~km}$ is compatible with depths of $16 \mathrm{~km}$ from the one-dimensional model and $16.5 \mathrm{~km}$ from the tau-sum models. An average depth of $19-20 \mathrm{~km}$ to the upper interface of the $6.9 \mathrm{~km} / \mathrm{s}$ layer at distance ranges between 50 and $100 \mathrm{~km}$ is comparable with the $21.7 \mathrm{~km}$ depth to a 6.8 $\mathrm{km} / \mathrm{s}$ velocity [see Lyslo and Nowack, this issue]. Overall the RMS error for this interface is $0.096 \mathrm{~s}$ (Figure 10a). This increase is caused primarily by an average $0.2 \mathrm{~s}$ misfit for the reflection correlation from profile 4 .

Approximately 250 rays at $1-\mathrm{km}$ intervals used for the inversion of the fourth interface (Moho) led to resolutions above 0.6 in regions of ray reflection off the Moho interface (Figures $11 a, 11 b$, and $11 c)$. The RMS travel time error of $0.1 \mathrm{~s}$ is an acceptable fit. The Moho interface determined from the inversion dips to the north between 0 and $50 \mathrm{~km}$. The lack of ray coverage between 0 and $25 \mathrm{~km}$ is mirrored by low resolutions at these node positions. The dip to the north, however, appears to be a necessary shape of the interface in order to fit data from profile 1 (shot point at $3.4 \mathrm{~km}$ ). The Moho interface is relatively flat between 50 and $200 \mathrm{~km}$. An average depth of 29.4 $\mathrm{km}$ between 100 and $150 \mathrm{~km}$ is close to the Moho depth from the one-dimensional model, the tau-sum velocity depth curves, and the slant stack results of Lyslo and Nowack [this issue].

The trade-off curve between spread of resolution and size of data-mapped covariance for the fourth interface inversion with 9 nodes is shown in Figure 12. Epsilon (damping) values between 0.1 and 0.5 are near the knee of this curve. The results discussed in this paper used an epsilon value of 0.3 . Empirically, lower values of epsilon begin to oscillate the interface depths without a corresponding improvement in travel time fit. Epsilon values above 0.3-0.5 significantly decrease cal- 


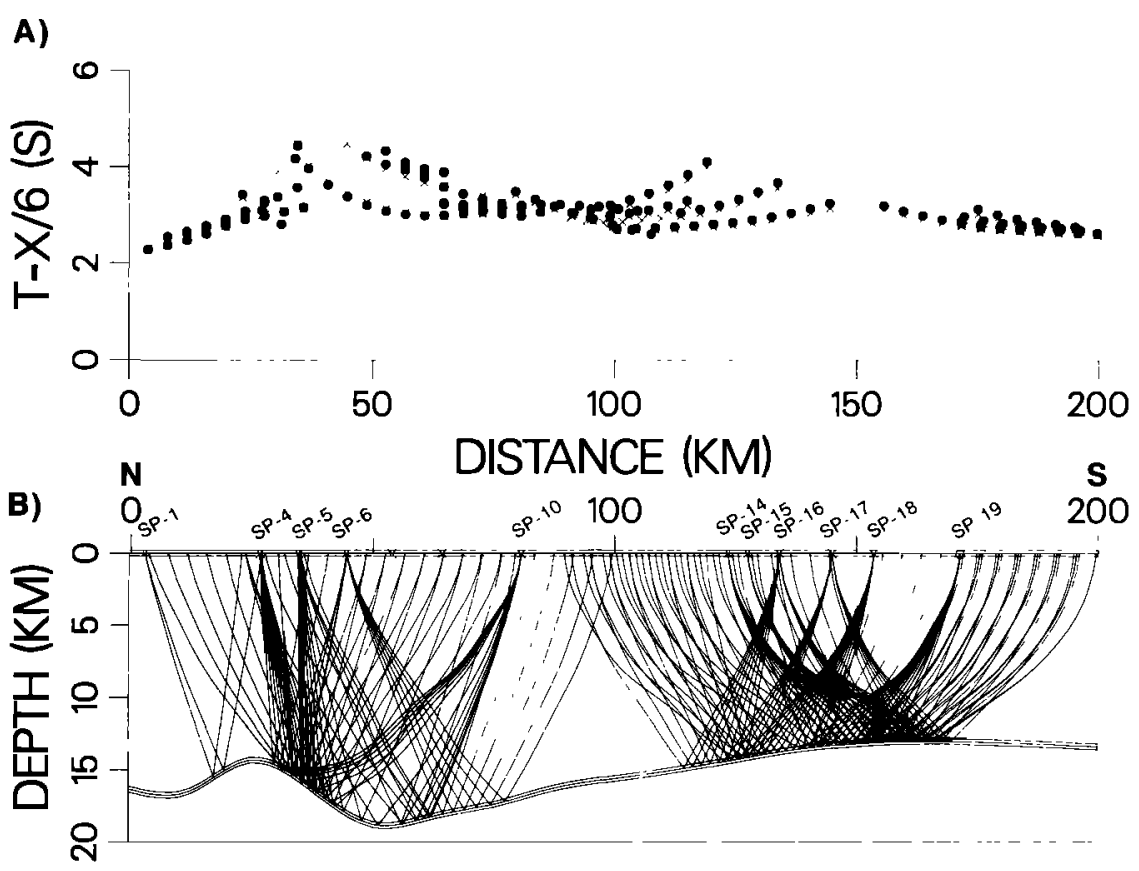

C)

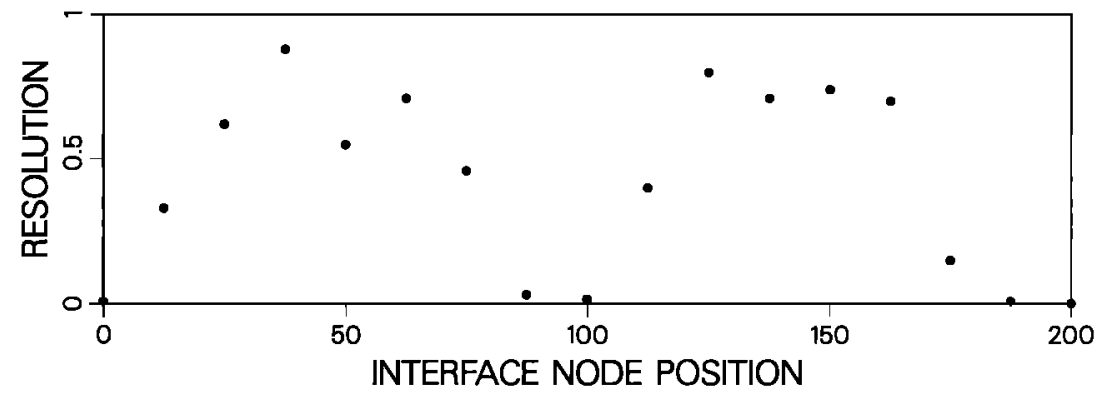

Fig. 7. (a) Comparison of 105 theoretical (inverted) travel times denoted by cross and synthetic data denoted by solid circle for final 17-node inversion model.' (b) Ray diagram of 17-node inversion model. (c) Resolutions for each node position are displayed for 17-node inversion.

culated resolutions such that resolutions above 0.5 no longer extend over regions of ray reflections.

Unlike forward modeling, an inversion allows a quantitative estimate of resolution and error of the individual model parameters. Figure 13 displays the final model and indicates which interface segments have acceptable resolution values $(\geq 0.6)$. Resolution values below 0.6 near the edges of the model at 0 $\mathrm{km}$ and $200 \mathrm{~km}$ and near a data gap centered at $100 \mathrm{~km}$ correspond to regions of low ray coverage. Interface segments with low-resolution values are not constrained by the inversion. In particular, the continuation of the second interface between the well-resolved northem and southern segments is not fully delineated by the inversion.

True errors associated with deeper crustal interface depths are likely to be significantly higher than a priori or a posteriori model standard errors based on an epsilon value from the tradeoff curve. Assuming an epsilon value of 0.3 and a data error of $0.075 \mathrm{~s}$, the a posteriori interface node depth errors will be less than the inferred a priori value of $0.25 \mathrm{~km}$. However, each layer interface is inverted for individually assuming the upper model interface positions and velocities are known exactly. A low signal to noise ratio as well as additional lateral velocity variations in the midcrustal layers further increase errors associated with interface position.

\section{MOdel Comparision}

Comparison of previous and concurrent geophysical studies to the final interface inversion model can be made. The final model may be directly compared to the interpretation of an overlapping Consortium for Continental Reflection Profiling (COCORP) reflection profile [Lillie et al., 1983] and other twodimensional models resulting from the analysis of the PASSCAL Ouachita data set [Plappert, 1988; Jardine, 1988; L.W. Braile et al., manuscript in preparation, 1990]. Refraction experiments within the same or nearby tectonic provinces [Warren et al., 1966; Stewart, 1968; Cram, 1962; Hales et al., 1970] also allow comparison of model results and provide indirect evidence concerning tectonic inferences.

Regional refraction data support the inference of a difference in crustal structure south of the Ouachita trend as evidenced by differences in Moho depth and lower crustal velocity. Normal continental crustal structure as inferred by the Stewart [1968] northem Missouri refraction profile contains a $20-\mathrm{km}$-thick 6.1 $6.2 \mathrm{~km} / \mathrm{s}$ upper crust and a $20-\mathrm{km}$-thick lower crust with a velocity of $6.6 \mathrm{~km} / \mathrm{s}$. South of the PASSCAL profile near the Texas-Louisiana border, Hales et al. [1970] determined a Moho depth of $49 \mathrm{~km}$ which near the Gulf Coast shallowed to $30 \mathrm{~km}$. A refraction survey in Mississippi [Worren et al., 1966] indiwhere most of the rays reflect from the interface. The root- 


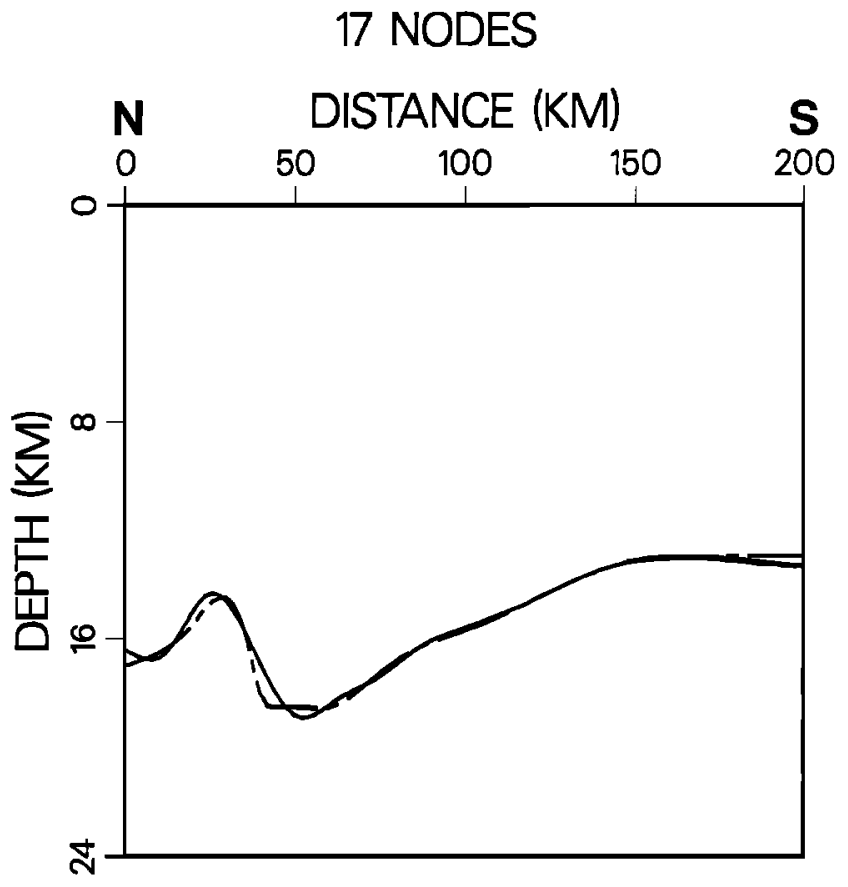

Fig. 8. Comparison of inverted interface with 17 nodes (solid curve) and original interface (dashed curve). The inverted interface has successfully imaged the original interface corrugation. cates a Moho depth of $30 \mathrm{~km}$ on an unreversed profile increasing in depth to $40 \mathrm{~km}$ near the Gulf Coast. The Moho was overlain by a $20-\mathrm{km}$-thick $6.9 \mathrm{~km} / \mathrm{s}$ layer.

Crustal structure of the final inverted model is compatible with previous seismic refraction interpretations south of the Ouachita trend. The Cram [1962] profile, parallel to and midway between the trend of the Ouachitas and the Gulf Coast, is in a position comparable to the PASSCAL profile. A 13-kmthick $6.9 \mathrm{~km} / \mathrm{s}$ layer was found to overlay a $8.2 \mathrm{~km} / \mathrm{s}$ mantle with a Moho depth of $35 \mathrm{~km}$. Similar results are observed in the final inverted model (Figure 13): a $29.5-\mathrm{km}$-deep Moho overlain by a $11.5-\mathrm{km}$-thick $6.9 \mathrm{~km} / \mathrm{s}$ layer between a position of 100 and $150 \mathrm{~km}$ on the PASSCAL profile.

The lack of a $6.2 \mathrm{~km} / \mathrm{s}$ layer in other refraction interpretations south of the Ouachitas may be caused by low data density or unreversed profiles. Less than 15 stations were positioned between shot points $200 \mathrm{~km}$ apart in the Cram [1962] survey. Although the Warren et al. [1966] survey was recorded by 200 stations along a $400-\mathrm{km}$ profile, the northern half of the survey was unreversed. However, a $6.3 \mathrm{~km} / \mathrm{s}$ refracter was interpreted from the unreversed profile north of Raleigh, Mississippi.

An interpretation of the COCORP Ouachita reflection profile by Lillie et al. [1983] indicates the presence of a buried Paleozoic continental margin within the northemmost portion of the PASSCAL profile. The northern $45 \mathrm{~km}$ of the PASSCAL profile overlaps the southern third of the COCORP reflection profile.
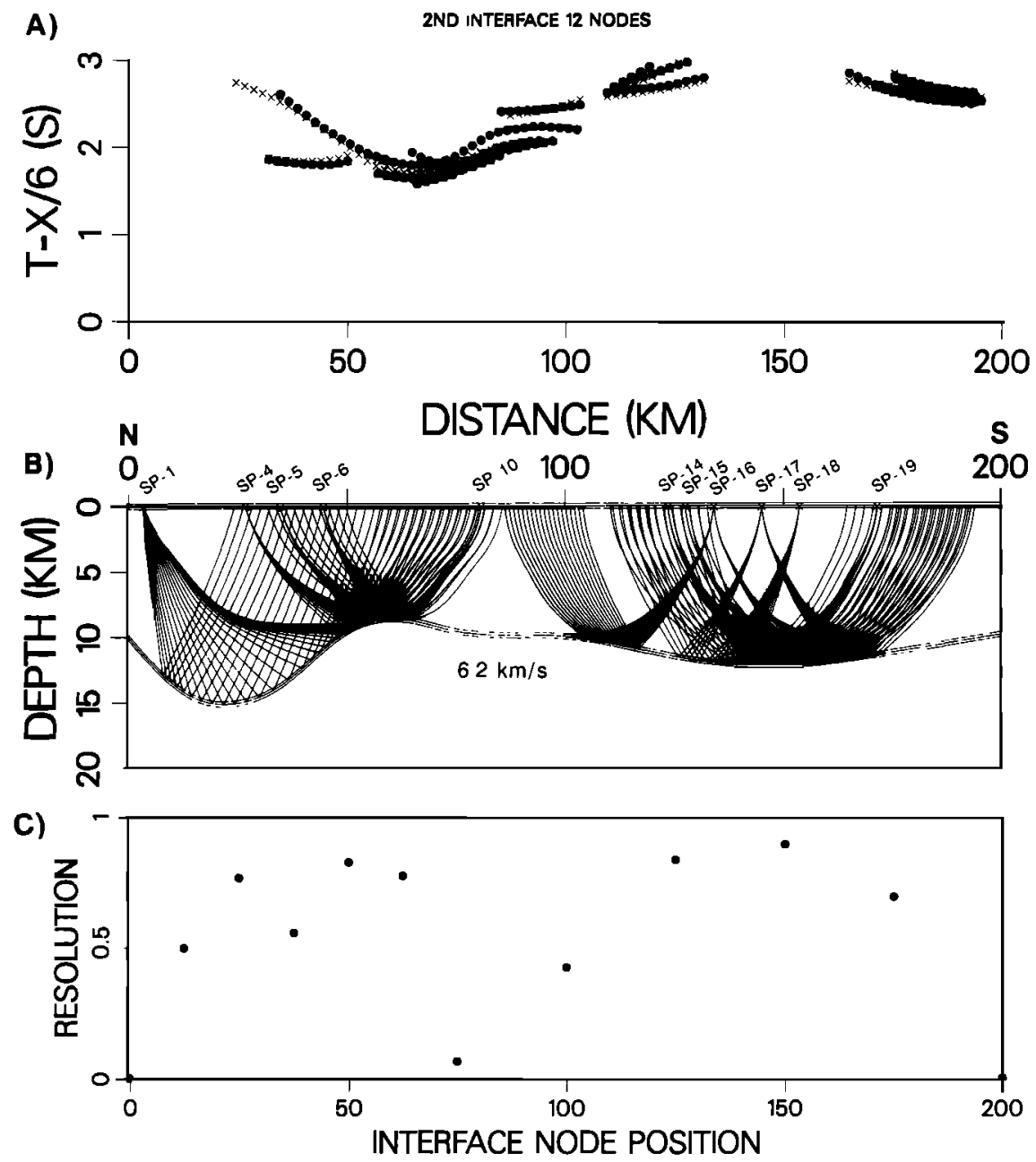

Fig. 9. (a) Comparison of theoretical (inverted) travel times (cross) and observed travel times (solid circle) for the 12-node inversion of the second interface. Every second travel time is displayed. (b) Ray diagram of 12-node model for second interface (upper interface of $6.2 \mathrm{~km} / \mathrm{s}$ layer). Every second ray is displayed. (c) Resolution for 12-node inversion. 

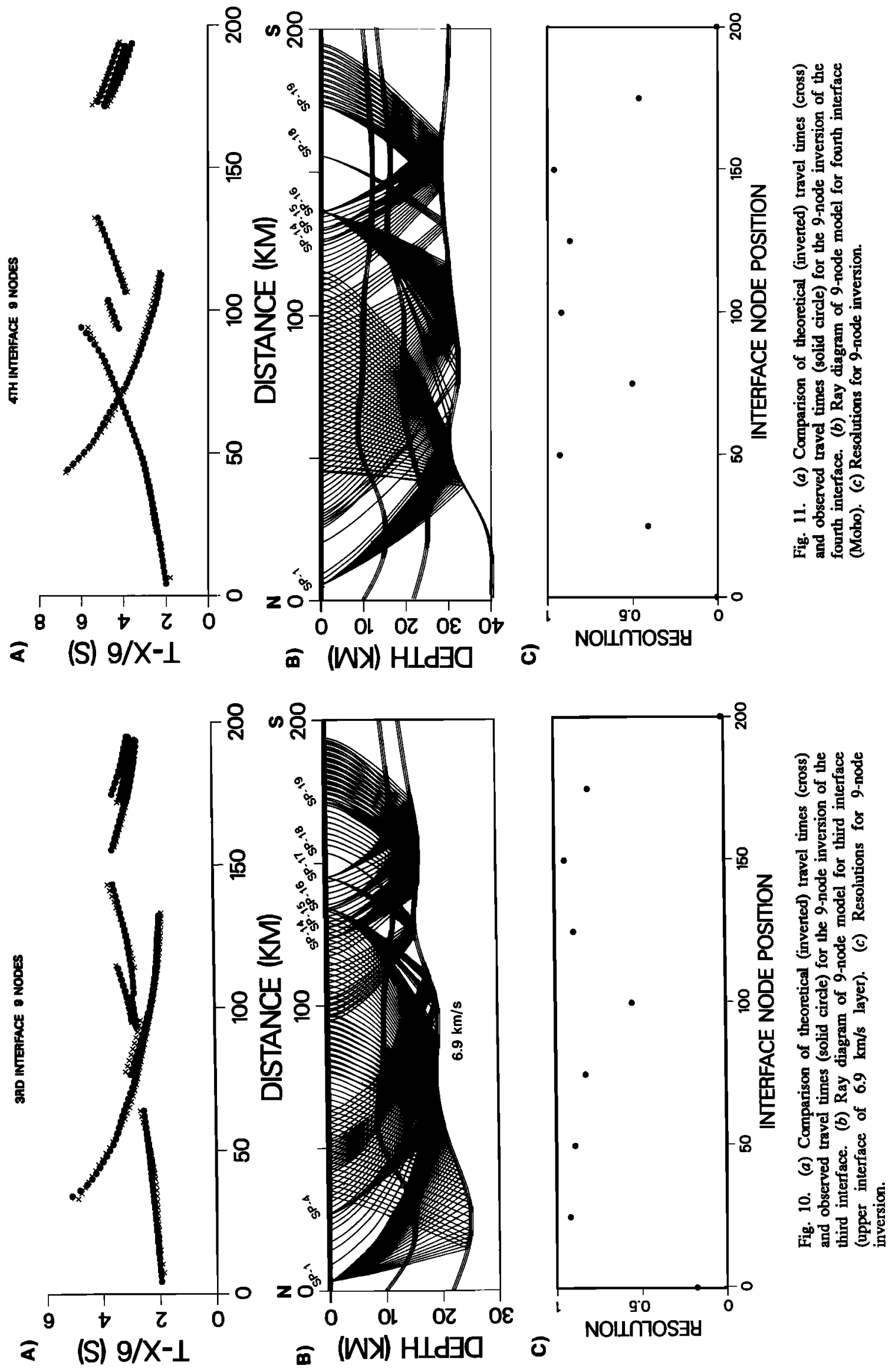
TRADE-OFF CURVE

OF RESOLUTION AND VARIANCE

FOR NINE NODE INTERFACE MODEL

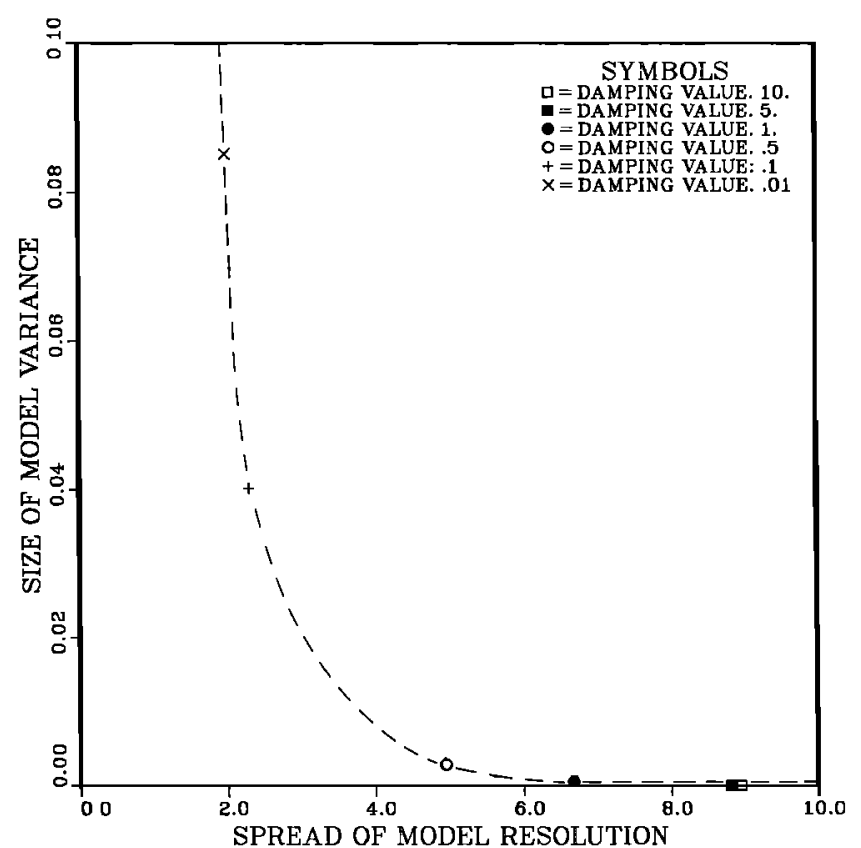

Fig. 12. Plot of spread of resolution versus size of covariance as defined by Menke [1984]. Damping values near the knee of the curve optimize the trade-off between model resolution and model variance.

Lillie et al. [1983] and Lillie [1985] interpret the Benton uplift, a basement high, to have an antiformal expression at depth and to have along its southern flank a volcanic wedge marking the oceanic-continental crustal boundary. A gravity maximum which may also identify the edge of the Paleozoic continental margin along the trend of the Ouachita system [Kruger and Keller, 1986] occurs approximately at the southern end of the
COCORP profile. This is coincident as seen in Figure 13 with shallowing of the Moho to $30 \mathrm{~km}$ depth at a range of $50 \mathrm{~km}$.

Interface depths at distances between 0 and $45 \mathrm{~km}$ may be compared to a line drawing interpretation of the COCORP Ouachita reflection profile by Lillie et al. [1983]. Two-way travel times from the line drawing have been converted to depth using velocities from Lutter et al. [this issue]. The trend of depths calculated for the base of the interpreted volcanoclastic wedge (upper interface of the Precambrian basement) matches with the position of the third interface (upper interface of the $6.9 \mathrm{~km} / \mathrm{s}$ layer) at distances between 0 and $45 \mathrm{~km}$. At $25 \mathrm{~km}$ the match is within a kilometer. Reflections extending to two way times of 4-5 s have been interpreted by Lillie et al. [1983] as imbricate thrust faults within allocthonous Paleozoic deep water sediments. The maximum depth of these interpreted faults roughly coincide with the upper interface of the $6.2 \mathrm{~km} / \mathrm{s}$ layer within several kilometers.

In Figure 14, features of the final interface inversion model are compared with a line drawing from Plappert [1988], who performed a normal moveout (NMO) stack of near-vertical to wide-angle reflections from the PASSCAL data set. Interface positions from the inverted model (solid lines) agree well with the trends of reflectors from the line drawing. Discrepancies are due to an approximate depth conversion used in the line drawing. In addition, some reflection events are multiples as evidenced by the packages of reflected arrivals. The inversion model is also in good agreement with the crustal structure determined by forward ray tracing [Jardine, 1988; Keller et al., 1989]. A comparison of the crustal velocity models derived from these different methods is given by L.W. Braile et al. (manuscript in preparation, 1990). Plappert [1988] found a dip to the north on the Moho and a depth to Moho of $30 \mathrm{~km}$ in the southern portion of the PASSCAL profile in approximate agreement with the final inversion model. Most deep crustal reflectors from the line drawing occur within the $6.9 \mathrm{~km} / \mathrm{s}$ layer from the inverted model. The line drawing in the northern 50 $\mathrm{km}$ images details of the Paleozoic continental margin not

\section{INVERSION MODEL}

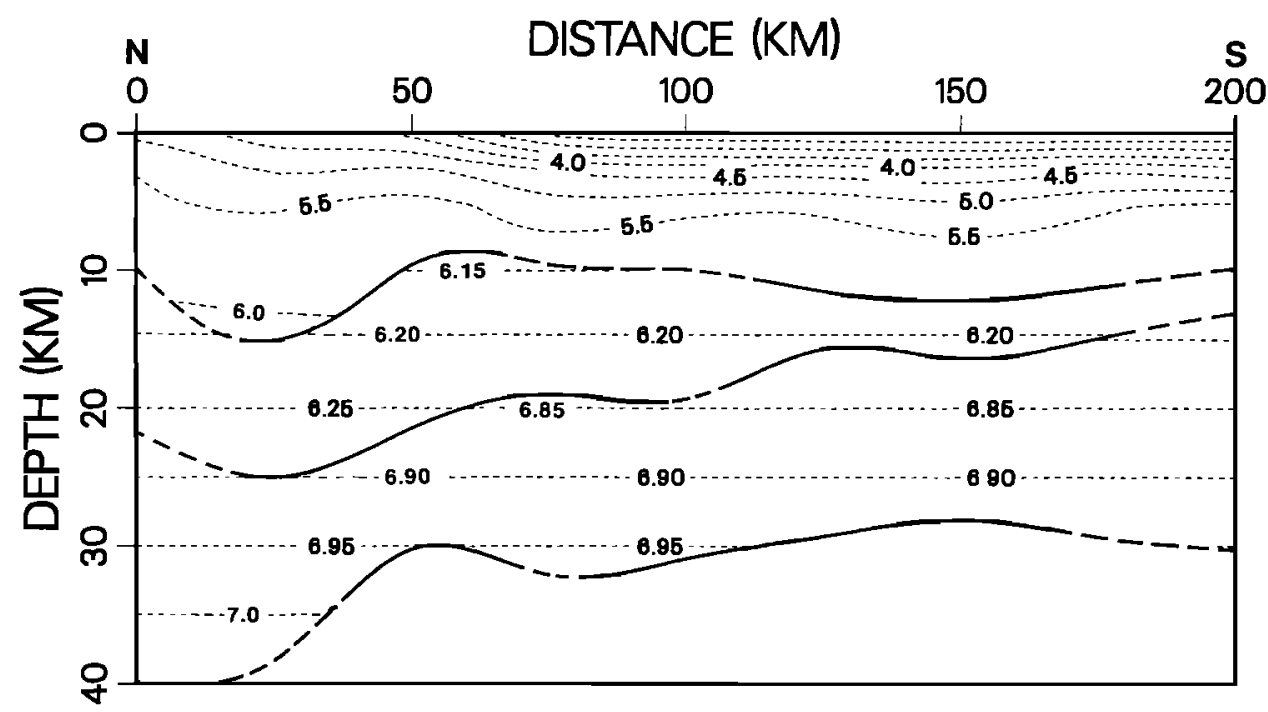

Fig. 13. Diagram of final model indicates which interface segments have acceptable resolution values $(\geq 0.6)$. Solid interface lines are associated with resolution values greater than 0.6 . Dashed interface lines are associated with resolution values less than $\mathbf{0 . 6}$. 


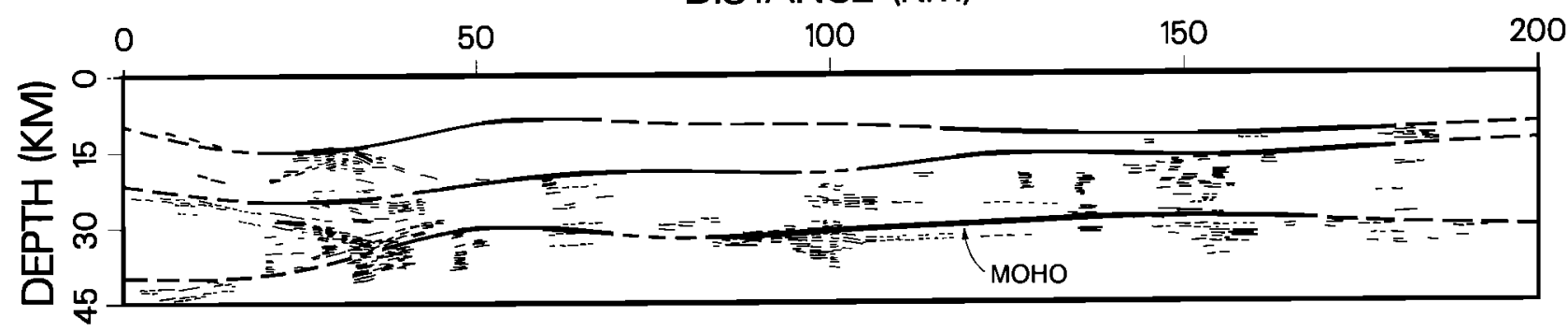

Fig. 14. Comparison of inversion interface position with a line drawing produced from individual shot point gathers corrected for normal moveout [from Plappert, 1988]. Dashed lines indicate where the resolution is less than 0.6. Inversion derived interface positions are in good agreement with the trend of reflectors from the line drawing.

resolved by the inversion model. These details include a probable boundary between continental crust to the north and transitional crust to the south. Although layers with average velocities of 6.2 and $6.9 \mathrm{~km} / \mathrm{s}$ in the inversion model extend over the entire length of the PASSCAL profile, the layers do not necessarily imply continuous geologic or tectonic units. Rather, the inversion model delineates zones of smoothly varying velocities and the configuration of interfaces between these zones.

\section{TECTONIC INTERPRETATION}

Tectonic interpretation of geological and geophysical evidence associated with the Ouachita orogenic belt [Lillie et al., 1983, Viele, 1979; Thomas, 1985] usually include Eocambrian rifting resulting in a passive continental margin, a Carboniferous orogeny involving the accumulation and deformation of a large volume of deep-water sediments and Triassic rifting. However, interpretations vary with respect to polarity of subduction during convergence and the identification of the southern plate. In recent years, a number of models have been proposed involving an Atlantic type continental margin subducting to the south beneath either an island arc system, a microcontinent, or a larger continental mass [Walper, 1977; Nelson et al., 1982; Lillie et al., 1983]. The identification of rhyolitic flows with late Paleozoic age dates [Nicholas and Waddell, 1982] from two wells on the southern flank of the Sabine uplift, which is just south of the PASSCAL profile have led to the favoring of southward subduction.

A southern land mass inferred from geologic constraints has been referred to as Llanoria since the early part of this century. Lillie et al. [1983] have suggested a southem plate microcontinent, Llanoria, to be positioned in Louisiana between the current and Paleozoic continental margin. Mesozoic rifting which opened the Gulf of Mexico may have occurred much closer to the Ouachita trend in southeast Texas [Lillie et al., 1983], leaving behind the Llanorian terrane south of the PASSCAL profile and the Sabine uplift.

Features of the PASSCAL Ouachita inversion model may be related to detailed studies of the modern Atlantic continental margin. Based on structural and geophysical studies, Klitgord et al. [1988] summarized the relationships between the structural framework of Atlantic margins and their deep crustal structure. Although later tectonic events have influenced the crustal structure beneath the PASSCAL Ouachita profile, a comparison to geophysical studies of a modern day passive margin is the simplest and probably the most significant comparison that can be made.

The crustal structure associated with the evolution of a passive margin includes hybrid crust between continental crust and oceanic crust. Based on seismic and potential field studies, several crustal zones have been inferred along the U.S. Atlantic margin [Klitgord et al., 1988; Trehu et al., 1989]. Boundaries between zones represent changes in the morphology of the basement and associated shallow crustal structure but do not necessarily represent vertical discontinuities [Trehu et al., 1989]. These crustal zones include continental crust, rifted continental crust, rift stage crust, marginal oceanic crust, and oceanic crust.

Geophysical features of the shallow crustal structure associated with boundaries between crustal zones along the U.S. Atlantic margin include a basement hinge zone and the seaward edge of the paleoshelf. These features may be separated by 50 km to several hundred kilometers. Rifted continental crust is positioned landward of the hinge zone, whereas rift stage crust is seaward of the hinge zone. Seaward of the paleoshelf edge by several tens of kilometers, is the transition from rift stage crust to marginal oceanic crust. The hinge zone is where basement deepens rapidly in a seaward direction from 2 to $4 \mathrm{~km}$ to over $8 \mathrm{~km}$ in depth. The position of the hinge zone usually is where the Moho begins to significantly shallow.

The crustal zones of the Atlantic margin have distinctive seismic characteristics [Diebold and Stoffa, 1988; White et al., 1987]. The variability in crustal structure for the rifted continental crust zone precludes its identification on the basis of velocity structure [Klitgord et al., 1988]. However, rift stage crust which has been intensely deformed by rifting has distinctive seismic characteristics. It is thinner than rifted continental crust and is characterized by a 9 - to $15-\mathbf{k m}$-thick layer just above the Moho with seismic velocities ranging from 7.1 to 7.6 $\mathrm{km} / \mathrm{s}$ [Klitgord et al., 1988]. Finally, marginal oceanic crust is positioned landward of oceanic crust and has a crustal thickness of approximately $10 \mathrm{~km}$ which is slightly greater than oceanic crust.

Seismic characteristics of crustal zones and probable identification of paleostructural features allows the classification of crustal structure imaged by the PASSCAL Ouachita interface inversion. The shallowing of the Moho suggests that the Paleozoic hinge zone was positioned within the northemmost $50 \mathrm{~km}$ of the PASSCAL Ouachita profile where sediments thicken to at least $10 \mathrm{~km}$. Seaward of this hinge zone the $11-$ to $13-\mathrm{km}$-thick $6.9 \mathrm{~km} / \mathrm{s}$ layer matches the typical thickness of the lower crustal layer overlying the Moho in rift stage crust. Although the 6.9 $\mathrm{km} / \mathrm{s}$ velocity is slightly lower than typical rift stage lower crust, average velocities as high as $7.2 \mathrm{~km} / \mathrm{s}$ are within the estimated constraints. Based on this analogy to the Atlantic coast margin, the crust imaged by the interface inversion is interpreted to be rift stage crust. However, other tectonic interpretations are possible given the uncertainties in velocity and lithology relationships [Keller et al., 1989]. 
Within the northem $45 \mathrm{~km}$ of the PASSCAL Ouachita experiment, a lower crustal boundary between rift stage crust to the south and rifted continental crust to the north should occur. Details of the reflection line drawing [Plappert, 1988] have been used to delineate this boundary as drawn in Figure 15. Labels uc and lc denote upper crustal and lower crustal layers of rifted continental crust. However, resolution in this part of the model is poor. The upper crust, uc, most likely includes Ouachita facies and volcanoclastic sediments as interpreted by Lillie et al. [1983] and fragments of continental crust. The lower crust, lc, correlates with precambrian basement at the extreme northern end of the PASSCAL profile. Dashed lines in Figure 15 indicate where the interface node resolution and consequently model reliability is low.

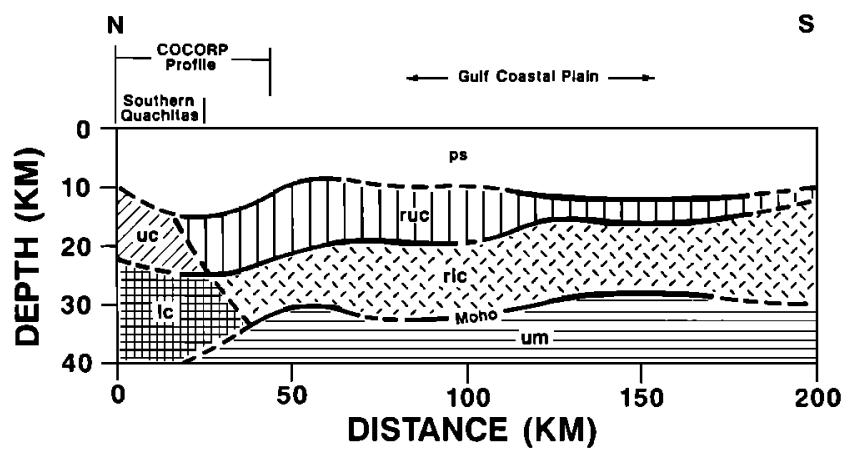

Fig. 15. Schematic tectonic model based on analogy to Atlantic continental margin. Dashed lines indicate where resolution is less than 0.6. Labels are uc, rifted continental upper crust; lc, rifted continental lower crust; ruc, rift stage upper crust; rlc, rift stage lower crust; ps, mostly deep water Paleozoic sediments with upper $3-4.5 \mathrm{~km}$ of Mesozoic and Cenozoic sediments (see Lutter et al. [this issue] for more detail); and um, upper mantle.

The layers associated with rift stage crust have been delineated on the basis of potential field studies (summarized by Sheridan et al. [1988]). The upper crustal layer in these models often thins seaward. Labels ruc and rlc in Figure 15 are for rifted upper and lower crust, respectively. The $6.2 \mathrm{~km} / \mathrm{s}$ layer thins from a thickness of $10 \mathrm{~km}$ between 50 and $100 \mathrm{~km}$ distance range to a thickness of $4 \mathrm{~km}$ for distances greater than $125 \mathrm{~km}$. The closest analogy from the Atlantic coast margin studies is a composite velocity model of the Baltimore Canyon trough displayed in Figure $13 b$ of Trehu et al. [1989]. In that model a prerift upper crustal layer thins from $10 \mathrm{~km}$ to of the order of $5 \mathrm{~km}$ between the hinge zone and the paleoshelf edge. This layer overlays the characteristic rift stage lower crustal layer.

This analogy to the present-day Atlantic continental margin cannot account for deep crustal modification due to later tectonic events especially late Paleozoic subduction/orogeny. It is widely accepted that the Paleozoic Ouachita facies originally deposited in a oceanic basin was overthrust to the north during the subduction/orogenic event [Houseknecht and Kacena, 1983]. The upper layer, shown in Figure 15, labeled ps, is composed mostly of these sediments but includes $4-5 \mathrm{~km}$ of Mesozoic and Cenozoic sediments in the southem two-thirds of the profile. A more detailed discussion of this portion of the model as imaged by a first arrival travel time inversion is given by Lutter et al., [this issue]. Based on the interpretation of rift stage crust beneath the central portion of the PASSCAL profile, the suture associated with this late Paleozoic subduction/orogenic event would occur south of the PASSCAL Ouachita profile. Loss of resolution at distances greater than $150-175 \mathrm{~km}$ preclude determining whether the crust shallows to normal oceanic thickness south of the PASSCAL profile or thickens due to the presence of Llanorian terrane.

\section{SUMMARY}

The application of inversion methods to multiple shot refraction data sets improves data fitting and gives a statistical measure of resolution and covariance of model parameters. The incorporation of an interface inversion into the earlier inversion scheme of Lutter et al. [this issue] allows the use of secondary reflected and refracted information to determine deeper crustal structure with model parameterizations which include velocity discontinuities at interfaces. The advantages of such an inversion scheme include the facilitation of modeling a large volume of data such as the PASSCAL Ouachita experiment with a more realistic model parameterization.

The use of a bicubic spline parameterization of the velocity model permits lateral and vertical gradients within layers. Layers are separated by splined interfaces and therefore velocity discontinuities can also be incorporated within the model. The general nonlinear inversion procedure followed here is a layerstripping approach for model parameters describing velocity within crustal layers or interface position at successively greater depths.

Partial derivatives of travel time with respect to interface depth are determined by calculating and storing the spline coefficients for each perturbed interface node. The interface inversion is tested using synthetic data generated with the same shot-receiver geometry as the PASSCAL experiment. Rays were reflected from a corrugated interface with a relief of $4 \mathrm{~km}$ and a width of $30 \mathrm{~km}$. A 17-node inversion successfully imaged this interface structure.

Travel time correlations were picked to match significant trends on AGC processed common shot gathers and are consistent with reciprocity constraints. Velocity-depth curves derived for shot points 14-19 using the tau-sum method are similar to an average one-dimensional velocity structure from preliminary forward modeling using travel time correlations from profiles 14-19. The similarity of these velocity-depth curves positioned over the southern half of the PASSCAL experiment suggests that crustal structure in this region is approximately laterally homogeneous. However, lower crustal velocities are not as well resolved due to the recording on most profiles of only small segments of the travel time triplications.

The average one-dimensional velocity model was extrapolated to a two-dimensional velocity structure by assuming velocities for deeper crustal layers and inverting for depth to interfaces. Velocity gradients with average velocities of 6.2 and $6.9 \mathrm{~km} / \mathrm{s}$ were used for deeper crustal layers. Laterally varying velocities in the uppermost layer were based on a first arrival travel time inversion [Lutter et al., this issue].

The final inversion model was found to be consistent with previous refraction interpretations south of the Ouachita orogenic trend and concurrent interpretations of the PASSCAL data set. Crustal structure is approximately laterally homogeneous over the southem half of the PASSCAL profile. Inversion results for the southern half indicate a depth of 10-12 km for a midcrustal layer which thins southward from approximately 10 $\mathrm{km}$ to about $4 \mathrm{~km}$. A lower crustal layer with an average thickness of $12.5 \mathrm{~km}$ and a Moho depth of approximately $29.5 \mathrm{~km}$ are also determined. Interface depths compare well with a NMO 
stack of the PASSCAL data set [Ploppert, 1988]. In particular, the shallowing to the south of the Moho over the northem $\mathbf{5 0}$ $\mathrm{km}$ of the profile matches previous interpretations of the data set and has been interpreted here and in previous studies as the location of the Paleozoic continental margin.

Geophysical studies of the modern Atlantic coast passive margin provide the simplest comparison with the inverted crustal structure. A 12-km-thick lower crustal layer south of the shallowing of the Moho to $30 \mathrm{~km}$ suggests the identification of this portion of the crust beneath the PASSCAL Ouachita profile as rift stage crust. However, other tectonic interpretations are possible given the uncertainties in velocity and lithology relationships [Keller et al., 1989]. The lack of resolution in the southernmost portion of the PASSCAL Ouachita profile precludes the identification of crustal type immediately south of the profile. Further geophysical investigations are necessary to delineate crustal structure across Llanoria to the present coastal margin.

Acknowledgments. This research was supported by National Science Foundation grants EAR-8518147, EAR-86-42240/X, EAR-8904169 and a Purdue University David Ross Fellowship. The authors thank L.W. Braile for many useful discussions. The manuscript was greatly improved from critical reviews by K. Roy-Chowdhury, W.D. Mooney, and an anonymous reviewer.

\section{REFERENCES}

Aki, K., and P.G. Richards, Quantitative Seismology, vol. 2, W.H. Freeman, New York, 1980.

Ankeny, L.A., L.W. Braile, and K.H. Olsen, Upper crustal structure beneath the Jemez Mountains volcanic field, New Mexico, determined by three-dimensional simultaneous inversion of seismic refraction and earthquake data, J. Geophys. Res., 91, 6188-6198, 1986.

Benz, H.M., and R.B. Smith, Simultaneous inversion for lateral velocity variations and hypocenters in the Yellowstone region using earthquake and refraction data, J. Geophys. Res., 89, 1208-1220, 1984.

Bishop, T.N., K.P. Bube, R.T. Cutler, R.T. Langan, P.L. Love, J.R. Resnick, R.T. Shuey, D.A. Spindler, and H.W. Wyld, Tomographic determination of velocity and depth in laterally varying media, Geophysics, 50, 903-923, 1985.

Červeny, V., and I. Psencik, Documentation of earthquake algorithms, SEIS83-Numerical Modeling of Seismic Wave Fields in 2-D Laterally Varying Layered Structures by the Ray Method, edited by E.R. Engdahl, REP. SE-1S, pp. 36-40, World Data Center (A) for Solid Earth Geophysics, Boulder, Colo., 1984.

Cerveny, V., I.A. Molotkov, and I. Pšenčík, Ray Method in Seismology, Vydala, Universita Karlova, Prague, Czechoslovakia, 1977.

Cram, I.H., Crustal structure of Texas Coastal Plain region, Am. Assoc. Pet. Geol. Bull., 46, 1721-1727, 1962.

Diebold, J.B., and P.L. Stoffa, The travel-time equation, tau-p mapping, and inversion of common midpoint data, Geophysics, 46, 238-254, 1981.

Diebold, J.B., and P.L. Stoffa, A Large Aperture Seismic Experiment in the Baltimore Canyon Trough, in The Geology of North America, vol. 1-2, The Allantic Continental Margin U.S., edited by R.E. Sheridan and J.A. Grow, pp. 19-55, Geological Society of America, Boulder, Colo., 1988.

Elbring, GJ., A method for inversion of two-dimensional seismic refraction data with applications to the Snake River plain region of Idaho, Ph. D. thesis, 124 pp., Purdue Univ., West Lafayette, Ind., 1984.

Ellsworth, W.L., and R.Y. Koyanagi, Three-dimensional crust and mantle structure of Kilauea Volcano, Hawaii, J. Geophys. Res., 82, 53795394, 1977.

Fuchs, K., and G. Mueller, Computation of synthetic seismograms with the reflectivity method and comparison with observations, Geophys. $J$. $R$. Astron. Soc., 23, 417-433, 1971.

Hales, A.L., C.E. Helsley, and J.B. Nation, Crustal structure study on Gulf Coast of Texas, Am. Assoc. Pet. Geol. Bull., 54, 2040-2057, 1970.

Houseknecht, D.W., and J.A. Kacena, Tectonic and sedimentary evolution of the Arkoma foreland basin, in Tectonic-Sedimentary Evolution of the Arkoma Basin, vol. 1, edited by D.W. Houseknecht, Pp. 3-33,
Midcontinent Section, Society of Economic Paleontologists and Mineralogists, St. Louis, MO, 1983.

Huang, H., C. Spencer, and A. Green, A method for inversion of refraction and reflection travel-times for laterally varying velocity structures, Bull. Seismol. Soc. Am., 76, 837-846, 1986.

Jardine, W.G., Seismic reflection-refraction study over the southem margin of the Ouachita system of Arkansas and the adjacent Gulf coastal plain, M.S. thesis, 112 pp., Purdue Univ., West Lafayette, Ind., 1988.

Kanasewich, E.R., and S.K.L. Chiu, Least-squares inversion of spatial seismic refraction data, Bull. Seismol. Soc. Am., 75, 865-880, 1985.

Keller, G.R., L.W. Braile, G.A. McMechan, W.A. Thomas, S.H. Harder, W.F. Chang, and W.G. Jardine, The Paleozoic continent-ocean transition in the Ouachita Mountains imaged from PASSCAL wideangle seismic reflection-refraction data, Geology, 17, 119-122, 1989.

Kind, R., The reflectivity method for a buried source, J. Geophys., 44, 603-612, 1978.

Klitgord, K.D., D.R. Hutchinson, and H. Schouten, U.S. Atlantic continental margin: Structural and tectonic framework, in The Geology of North America, vol. 1-2, The Allantic Continental Margin U.S., edited by R.E. Sheridan and J.A. Grow, pp. 19-55, Geological Society of America, Boulder, Colo., 1988.

Kruger, J.M., and G.R. Keller, Interpretation of crustal structure from regional gravity anomalies, Ouachita Mountains area and adjacent Gulf coastal plain, Am. Assoc. Pet. Geol. Bull, 70, 667-689, 1986.

Lillie, R.J., Tectonically buried continent/ocean boundary, Ouachita Mountains, Arkansas, Geology, 13, 18-21, 1985.

Lillie, RJ., K.D. Nelson, B. de Voogd, J.A. Brewer, J.E. Oliver, L.D. Brown S. Kaufman, and G.W. Viele, Crustal structure of Ouachita Mountains, Arkansas: A model based on integration of COCORP reflection profiles and regional geophysical data, Am. Assoc. Pet. Geol. Bull., 67, 907-931, 1983.

Lutter, W.J., R.L. Nowack, and L.W. Braile, Seismic imaging of upper crustal structure using travel times from the PASSCAL Ouschita experiment, J. Geophys. Res., this issue.

Lysio, J.A., and R.L. Nowack, Slant stack velocity analysis of shot point 16 from the 1986 PASSCAL Ouachita experiment, J. Geophys. Res., this issue.

McMechan, G.A., R.W. Clayton, W.D. Mooney, Application of wave field continuation to the inversion of refraction data, J. Geophys. Res., 87, 927-935, 1982.

Menke,W., Geophysical Date Analysis: Discrete Inverse Theory, 260 pp., Academic, San Diego, Calif., 1984.

Nelson, K.D., R.J. Lillie, B de Voogd, J.A. Brewer, J.E. Oliver, S. Kaufman, L. Brown, and G.W. Viele, COCORP seismic reflection profiling in the Ouachita Mountains of westem Arkansas: Geometry and geologic interpretation, Tectonics, 1, 413-430, 1982.

Nicholas, R.L. and D.E. Waddell, New Paleozoic subsurface data from the north-central Gulf coast (abstract), Geol. Soc. Am. Abstr. Programs, 14, 576, 1982.

Nolet, G., Solving or resolving inadequate and noisy tomographic systems, J. Comput. Phys., 61, 463-482, 1985.

Nowack, R.L., and W.J. Lutter, A note on the calculation of covariance and resolution, Geophys. J., 95, 205-207, 1988.

Nowack, R.L., and J. Lyslo, Frechet derivatives for curved interfaces in the ray approximation, Geophys. J., 97, 497-509,1989.

Paige, C.C., and M.A. Saunders, LSQR: An algorithm for sparse linear equations and sparse least squares, ACM Trans. Math. Software, 8 , 43-71, 1982

Plappert, J.W., Processing and interpretation of near vertical and wide angle seismic reflection data from the PASSCAL Ouachita lithospheric seismic study, M.S. thesis, 134 pp., Purdue Univ., West Lafayette, Ind., 1988.

Sheridan, R.E., J.A. Grow and K.D. Klitgord, Geophysical data, in The Geology of North America, vol. 1-2, The Atlantic Continental Margin U.S., edited by R.E. Sheridan and J.A. Grow, pp. 19-55, Geological Society of America, Boulder, Colo., 1988.

Spence, G.D., R.M. Clowes, and R.M. Ellis, Seismic structure across the active subduction zone of westem Canada, J. Geophys. Res., 90, 6754-6772, 1985.

Stewart, S.W., Crustal structure in Missouri by seismic refraction methods, Bull. Seismol. Soc. Am., 58, 291-323, 1968.

Thomas, W.A., The Appalachian-Ouachita connection: Paleozoic orogenic belt at the southem margin of North America, Annu. Rev. Earth Planet. Sci., 13, 175-199, 1985.

Trehu, A.M., A. Ballard, L.M. Dorman, J.F. Gettrust, K.D. Klitgord, and A. Schreiner, Structure of the lower crust beneath the Carolina 
Trough, U.S. Atlantic Continental Margin, J. Geophys. Res., 94, $10,585-10,600,1989$.

Viele, G.W., Geologic map and cross section, eastem Ouachita Mountains, Arkansas, Map Chart Ser. MC-28F, Geol. Soc. of Am., Boulder, Colo., 1979.

Walper, J.H., Paleozoic tectonics of the southem margin of North America, Trans. Gulf Coast Assoc. Geol. Soc., 29, 230-241, 1977.

Warren, D.H., J.H. Healy, and W.H. Jackson, Crustal seismic measurements in southem Mississippi, J. Geophys. Res., 71, 3437$3458,1966$.

White, R.S., G.K. Westbrook, A.N. Bowen, S.R. Fowler, G.D. Spence,
C. Prescott, P.J. Barton, M. Joppen, J. Morgan, and M.H.P. Bott, Hatton Bank (northwest U.K.) continental margin structure, Geophys. J. R. Astron. Soc., 89, 265-272, 1987.

W.J. Lutter and R.L. Nowack, Department of Earth and Atmospheric Sciences, Purdue University, West Lafayette, IN 47907.

(Received August 16, 1988; revised December 11, 1989; accepted December 12, 1989.) 